\title{
PEMANFAATAN SAMPAH PLASTIK MENJADI BRIKET SEBAGAI BAHAN BAKAR ALTERNATIF DALAM KILN DI PABRIK PT SEMEN PADANG
}

\author{
Hendri Sawir \\ Program Studi Teknik Lingkungan Sekolah Tinggi Teknologi Industri (STTIND) Padang \\ Email: hendri.sawir@yahoo.com
}

\begin{abstract}
Coal is a natural resource that can not be updated and will be depleted when used continuously. PT Semen Padang is a cement industries that use coal as fuel in large quantities which can increase production costs. It should be considered for alternative materials that can be used as fuel. The example is plastic waste that has tremendous potential as an alternative fuel. For that conducted research on the make of plastic waste into briquettes with technology Plastic Waste as alternative fuel to substitute for coal in the kiln PT Semen Padang from two types of plastic waste, is garbage plastic bags (PP) and a glass of mineral water plastic waste (PET). This study aims to determine the quality of briquettes, to obtain a picture of whether plastic pellets briquettes can be used as a substitute for coal and a comparison of the use of coal briquettes plastic pellets in the kiln PT Semen Padang. From the test, it is known that the briquettes garbage plastic bags have a calorific value of $10.112 \mathrm{cal} / \mathrm{gram}$, ash content of 3,90\%, 0,36\% moisture and volatile content of 94,74\%. And

briquettes from waste plastic glasses of mineral water has a calorific value of 10.844 cal/gram, ash content of 0,27\%, 0,42\% moisture and volatile content of 99,27\%. From these results it can be seen that the briquettes from waste glasses of mineral water has a better quality. And when compared with the specifications of coal used in the kiln Indarung IV calorific value 5200 - $5600 \mathrm{cal} / \mathrm{gram}$, maximum ash content of $20 \%$ and a maximum water content of $10 \%$, then the two types of briquette plastic pellets can be used as a fuel substitute for coal. Based on the comparison of calorific value and the use of coal in the kiln Indarung $I V$ which is an average of 35 tons / hour, then the ratio of the amount of usage of coal with briquettes from waste plastic bags is 1: 0.53, and with briquettes from waste plastic glasses of mineral water is $1: 0.50$.
\end{abstract}

Keywords: plastic waste, coal, briquettes, quality, fuel

\section{Pendahuluan}

Bahan bakar adalah suatu materi apapun yang bisa diubah menjadi energi. Salah satu contoh bahan bakar yang banyak digunakan dalam industri adalah batu bara. Batu bara merupakan sumber daya alam yang tidak dapat diperbaharui dan akan habis bila digunakan terus-menerus. PT Semen Padang yang merupakan sebuah industri persemenan yang menggunakan batu bara sebagai bahan bakar, tentunya membutuhkan pasokan batu bara dalam jumlah besar. Setiap hari PT Semen Padang menggunakan batu bara sebanyak \pm 3500 ton dalam proses produksinya. Penggunaan batu bara dalam jumlah besar juga akan meningkatkan biaya produksi. Jumlah batu bara yang terbatas dan biaya penyediaan batu bara yang besar merupakan masalah yang besar bagi industri seperti PT Semen Padang, untuk itu perlu dipikirkan bahan alternatif baru yang dapat digunakan sebagai bahan bakar. Salah satu contohnya adalah sampah plastik.

Potensi sampah plastik sebagai bahan bakar sangat besar sekali, mengingat jumlah timbulan sampah yang besar setiap harinya dan belum ditemukannya solusi yang tepat untuk penanggulangan sampah ini. Salah satu cara untuk menjadikan sampah plastik sebagai bahan bakar alternatif yaitu dengan membuat briket plastik.

Dari uraian di atas maka dapat dirumuskan masalah yang melatarbelakangi penelitian ini yaitu :

1. Apakah briket biji plastik dari jenis bahan baku yang berbeda mempunyai kualitas yang sama?

2. Apakah penggunaan batu bara di kiln pabrik PT Semen Padang dapat digantikan dengan briket biji plastik?

3. Berapakah perbandingan jumlah pemakaian batu bara dengan briket biji 
plastik di kiln pabrik PT Semen Padang?

Sesuai dari latar belakang dan rumusan masalah di atas, maka tujuan dari penelitian ini adalah untuk mengetahui kualitas briket biji plastik dari jenis bahan baku yang berbeda, memperoleh gambaran apakah batu bara dapat digantikan penggunaannya dengan briket biji plastik, dan untuk mengetahui perbandingan jumlah pemakaian batu bara dengan briket biji plastik di kiln pabrik PT Semen Padang.

\section{Tinjauan Pustaka}

Menurut SNI 19-2454-1991 tentang

Tata Cara Teknik Pengelolaan Sampah Perkotaan, sampah adalah limbah padat yang terdiri dari zat organik dan anorganik yang dianggap tidak berguna lagi dan harus dikelola agar tidak membahayakan lingkungan dan melindungi investasi pembangunan. Walaupun dianggap sudah tidak berguna dan tidak diinginkan lagi, namun sampah tersebut kadang-kadang masih dapat dimanfaatkan kembali dan dijadikan bahan baku produk lain. Salah satu contoh pemanfaatan sampah adalah dijadikan briket sebagai bahan bakar alternatif.

Briket merupakan sumber energi alternatif sebagai pengganti bahan bakar yang terbuat dari batu bara, limbah organik, limbah pabrik maupun dari limbah perkotaan dengan cara mengkonversi bahan baku padat menjadi suatu bentuk hasil kompaksi yang lebih efektif, efisien dan mudah digunakan (Asip $d k k, 2014$ ). Dalam penelitian ini briket dibuat dari sampah plastik. Briket dari sampah plastik dibuat dengan menggunakan alat teknologi briket sampah plastik yang mana prinsip kerja alat ini adalah dengan pemanasan pada suhu yang sesuai dengan titik lebur plastik yang digunakan sebagai bahan baku pembuatan briket plastik, kemudian dilakukan pendinginan briket yang dihasilkan dengan menggunakan air. Alat teknologi briket sampah plastik ini dirancang secara sederhana dan dibuat dengan memanfaatkan oven listrik bekas yang tidak dapat digunakan lagi. Dengan penambahan satu plat elemen pemanas pada bagian bawahnya menjadikan oven listrik berfungsi sebagai pemanas pada alat teknologi sampah plastik ini. Alat Teknologi Briket Sampah Plastik ini dapat dilihat pada gambar 2.1 berikut ini:

Plastik merupakan bahan anorganik buatan yang tersusun dari bahan-bahan kimia yang cukup berbahaya bagi lingkungan. Bahan pembuat plastik pada mulanya adalah minyak dan gas sebagai sumber alami, tetapi di dalam perkembangan zaman bahan-bahan ini digantikan dengan bahan sintesis sehingga dapat diperoleh sifat-sifat plastik yang diinginkan. Plastik memiliki dua sifat fisik, yaitu thermoplastic (plastik yang dapat didaur ulang atau dicetak lagi dengan proses pemanasan ulang) dan thermosetting (plastik yang tidak bisa didaur ulang atau dicetak lagi dengan proses pemanasan ulang). Jenis plastik yang digunakan dalam penelitian ini termasuk ke dalam golongan plastik yang memiliki sifat thermoplastic yaitu sampah kantong plastik yang termasuk ke dalam jenis plastik PP (polypropylene) dengan titik lebur pada suhu $160^{\circ} \mathrm{C}$ dan sampah plastik botol air mineral yang termasuk ke dalam jenis plastik PET (polyethylene terephthalate) dengan titik lebur lebih tinggi yaitu pada suhu $250^{\circ} \mathrm{C}$.

Briket sampah plastik yang dibuat sebagai bahan bakar alternatif pengganti batu bara akan digunakan dalam proses pembuatan semen. Bahan bakar ini digunakan untuk membakar produk rawmix untuk dijadikan klinker, yang mana ini merupakan tahap awal dalam pembuatan semen. Proses pembakaran ini terjadi di dalam kiln dengan suhu mencapai $1400^{\circ} \mathrm{C}$.

\section{Metodologi Penelitian}

Jenis penelitian yang digunakan dalam penelitian ini adalah penelitian eksperimen. Bahan yang digunakan adalah sampah kantong plastik dan sampah plastik botol air mineral. Dalam penelitian ini data yang digunakan adalah data primer dan data sekunder. Untuk data primer berasal dari hasil uji laboratorium kualitas briket biji plastik, sedangkan untuk data sekunder yang digunakan dalam pengolahan data adalah data spesifikasi batu bara fine coal kiln Indarung IV PT Semen Padang yang berasal dari data standar internal PT Semen Padang. Variabel dalam penelitian ini adalah nilai kalor bakar briket, kadar abu, kadar air dan kadar volatil. 

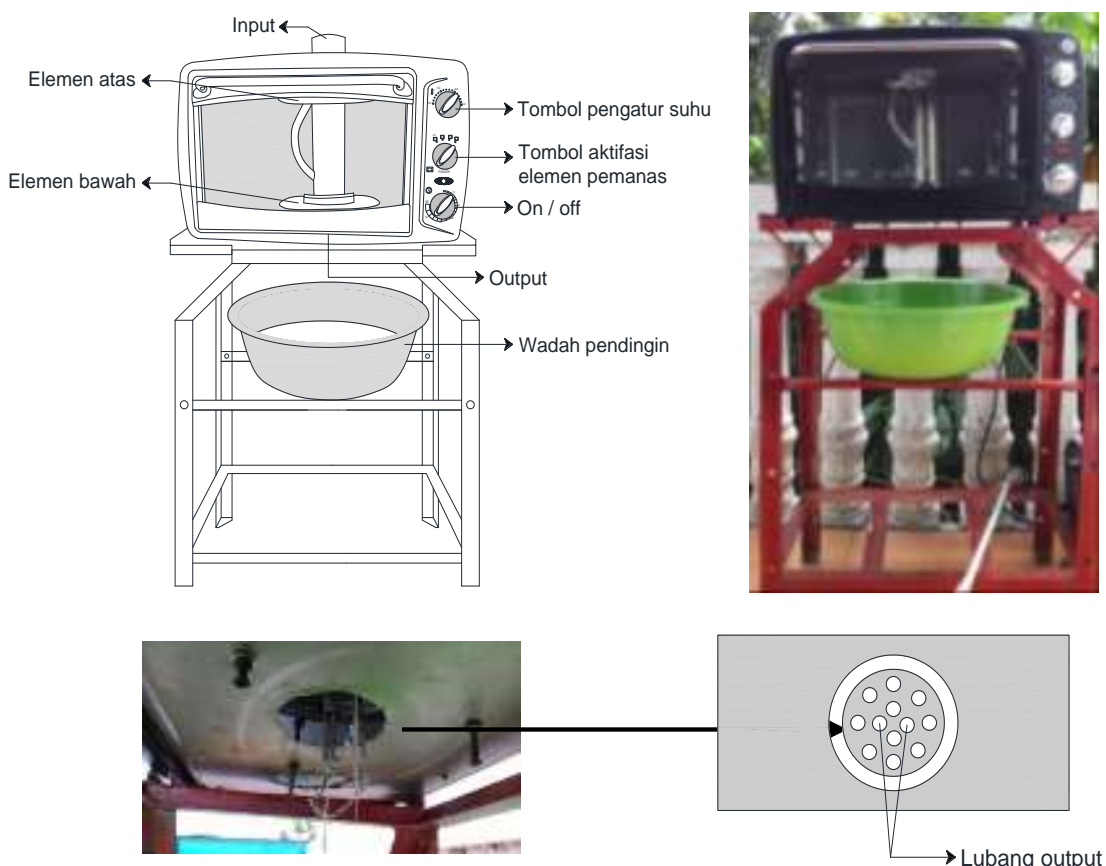

Gambar 2.1 Alat Teknologi Briket Sampah Plastik

Untuk pembuatan briket plastik, sampah plastik terlebih dahulu dicuci dan kemudian dikeringkan. Kemudian timbang sampah plastik sebanyak 500 gram dan masukkan ke dalam corong input alat Teknologi briket plastik yang telah diatur suhunya sesuai suhu titik lebur masing-masing jenis plastik. Briket plastik akan keluar melalui corong output dan langsung dilakukan pendinginan menggunakan air.

Pengujian terhadap kualitas briket plastik dilakukan dilaboratorium menggunakan alat Bomb Calorimeter PARR 1261 untuk pengujian kalor bakar, alat Minimum Free Space Oven untuk pengujian kadar air, dan furnace untuk pengujian kadar abu dan kadar volatil. Untuk pengolahan datanya menggunakan rumus sebagai berikut:

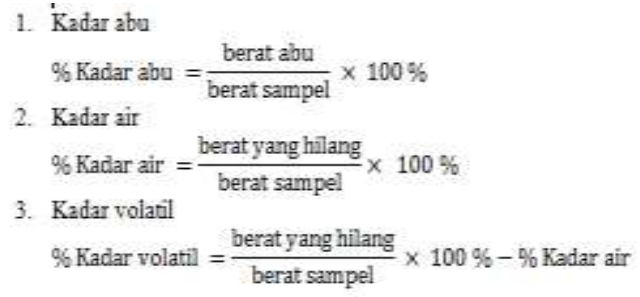

\section{Hasil dan Pembahasan}

Dari proses pembuatan briket dari sampah plastik menggunakan alat Teknologi briket plastik, maka dihasilkan berat briket yang terdapat pada tabel 4.1 berikut ini :
Tabel. 1 Waktu dan Berat Briket yang Dihasilkan dari Sampah Plastik

\begin{tabular}{|l|c|c|c|c|}
\hline \multicolumn{1}{|c|}{$\begin{array}{c}\text { Jenis } \\
\text { Plastik }\end{array}$} & $\begin{array}{c}\text { Berat } \\
\text { B. } \\
\text { Baku } \\
\text { (gram) }\end{array}$ & $\begin{array}{c}\text { Waktu } \\
\text { Pembuatan } \\
\text { (menit) }\end{array}$ & $\begin{array}{c}\text { Suhu } \\
\left({ }^{\circ} \mathrm{C}\right)\end{array}$ & $\begin{array}{c}\text { Berat } \\
\text { Briket } \\
\text { (gram) }\end{array}$ \\
\hline $\begin{array}{l}\text { Kantong } \\
\text { plastik } \\
\text { (PP) }\end{array}$ & 500 & 9 & 160 & 467 \\
\hline $\begin{array}{l}\text { Plastik } \\
\text { gelas air } \\
\text { mineral } \\
\text { (PET) }\end{array}$ & 500 & 13 & 250 & 458 \\
\hline
\end{tabular}

Dari berat sampah kantong plastik 500 gram menghasilkan briket sebanyak 467 gram, berarti terdapat pengurangan berat sebanyak 6,6\%. Dan dari 500 gram plastik gelas air mineral dihasilkan briket sebanyak 458 gram, berarti terdapat pengurangan berat sebanyak $8,4 \%$. Pengurangan berat ini mungkin disebabkan oleh adanya gas yang menguap akibat pemanasan yang dilakukan.

\section{Perbandingan Kualitas Briket Plastik}

Dari hasil pengujian di laboratorium terhadap kualitas briket plastik yang dihasilkan dapat dilihat pada table .2 :

Dari Tabel .2 di atas dapat dilihat bahwa kualitas briket dari sampah kantong plastik dan briket dari sampah plastik gelas air mineral telah memenuhi persyaratan kualitas briket berdasarkan SNI No. 1/6325/2000 dan juga kualitas briket plastik lebih baik dibandingkan dengan spesifikasi batu bara fine coal yang digunakan di kiln Indarung IV PT Semen Padang. Jadi briket 
Tabel. 2 Perbandingan Kualitas Briket Plastik

\begin{tabular}{|c|l|c|c|c|c|}
\hline No & Parameter & $\begin{array}{c}\text { Briket } \\
\text { Kanto } \\
\text { ng } \\
\text { Plastik }\end{array}$ & $\begin{array}{c}\text { Briket } \\
\text { Plastik } \\
\text { Gelas } \\
\text { Air } \\
\text { Mineral }\end{array}$ & SNI & $\begin{array}{c}\text { Spek. } \\
\text { FC Ind } \\
\text { IV }\end{array}$ \\
\hline 1 & $\begin{array}{l}\text { Kalor } \\
\text { Bakar } \\
\text { (kal/gr) }\end{array}$ & 10.112 & 10.844 & 5000 & $\begin{array}{c}\geq 000 \\
5600\end{array}$ \\
\hline 2 & $\begin{array}{l}\text { Kadar Abu } \\
(\%)\end{array}$ & 3,90 & 0,27 & $\leq 8$ & $\begin{array}{c}\text { Maks } \\
20\end{array}$ \\
\hline 3 & $\begin{array}{l}\text { Kadar Air } \\
(\%)\end{array}$ & 0,36 & 0,42 & $\leq 8$ & $\begin{array}{c}\text { Maks } \\
10\end{array}$ \\
\hline 4 & $\begin{array}{l}\text { Kadar } \\
\text { Volatil (\%) }\end{array}$ & 94,74 & 99,27 & - & - \\
\hline
\end{tabular}

Sumber : Pengujian laboratorium dan SNI No. $1 / 6325 / 2000$

Plastik dapat digunakan sebagai bahan bakar alternatif pengganti batu bara di kiln Indarung IV PT Semen Padang. Dan perbandingan nilai kalor bakar kedua jenis briket dapat dilihat dengan jelas pada Gambar 4.1 berikut ini :

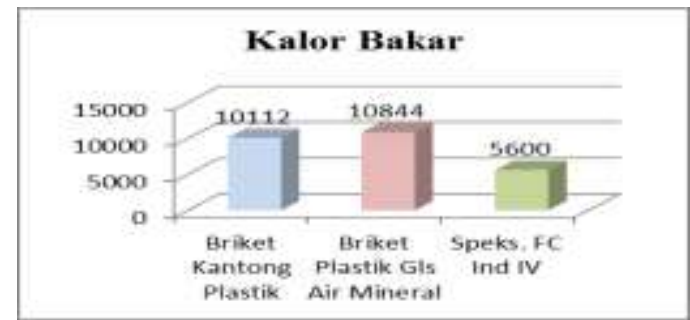

\section{Gambar .1 Perbandingan Nilai Kalor Bakar Briket Biji Plastik}

Dari gambar di atas terlihat bahwa nilai kalor bakar briket dari sampah plastik gelas air mineral lebih tinggi dari pada nilai kalor briket dari sampah kantong plastik. Nilai kalor suatu senyawa hidrokarbon terjadi karena adanya energi akibat reaksi kimia pemutusan ikatan antara atom-atom pada suatu senyawa yang bereaksi dan penggabungan kembali atom-atom yang bereaksi membentuk senyawa baru. Semakin panjang ikatan rantai atom suatu senyawa, maka energi yang dihasilkan juga semakin tinggi yang menyebabkan nilai kalor juga semakin tinggi. Briket kantong plastik yang terbuat dari plastik jenis Polipropilene (PP) memiliki rumus molekul $\left(\mathrm{C}_{3} \mathrm{H}_{6}\right)_{\mathrm{x}}$ dan rumus bangunnya adalah (-CH$\left.\mathrm{CH}_{3}-\mathrm{CH}_{2}\right)$ n. Dari rumus bangun tersebut terlihat bahwa plastik jenis PP memiliki ikatan rantai yang pendek, sehingga pada reaksi pemutusan ikatan atomnya menghasilkan energi yang kecil pula dibandingkan dengan briket plastik dari gelas air mineral yang terbuat dari jenis plastik Polietilene Tereptalate (PET). PET memiliki rumus molekul (-CO- $\mathrm{C}_{6} \mathrm{H}_{5}-\mathrm{CO}-\mathrm{O}-$ $\left.\mathrm{CH}_{2}-\mathrm{CH}_{2}-\mathrm{O}-\right)$ n. Dari rumus molekul tersebut dapat terlihat bahwa plastik PET memiliki ikatan rantai atom yang lebih panjang sehingga menghasilkan energi yang besar pula pada saat reaksi pemutusan rantai atomnya.

Dari Gambar .1 juga dapat dilihat bahwa nilai kalor bakar kedua jenis briket biji plastik melebihi nilai kalor bakar batu bara fine coal yang digunakan di kiln Indarung IV, sehingga briket biji plastik dapat digunakan sebagai pengganti batu bara di kiln Indarung IV PT Semen Padang.

Pada Gambar .2 dan Gambar .3 berikut ini dapat dilihat perbedaan kadar abu dan kadar air dari kedua jenis briket plastik yang telah di buat. Dari Gambar.2 terlihat bahwa kadar abu briket dari sampah kantong plastik 3,90\%, lebih tinggi dari kadar abu briket dari sampah plastik gelas air mineral yang hanya $0,27 \%$. Kadar abu menunjukkan banyaknya zat pengotor yang terdapat di dalam suatu material. Semakin rendah kadar abu suatu bahan bakar, maka semakin baik kualitas dari bahan bakar tersebut. Pada saat pemanasan semua senyawa hidrokarbon akan menguap, dan yang tertinggal sebagai kadar abu adalah senyawa logam yang tidak menguap pada saat pemanasan. Tingginya kadar abu pada briket sampah kantong plastik disebabkan karena kantong plastik sendiri merupakan plastik daur ulang, yang mana zat-zat pengotor akan banyak terbawa pada saat proses pendaur ulangannya.

Dari Gambar .3 juga terlihat perbedaan kadar air pada kedua jenis briket biji plastik yang disebabkan oleh faktor eksternal dari briket yang terjadi pada saat proses pembuatan briket. Karena pada proses pembuatan briket membutuhkan pendinginan dengan air agar briket lebih cepat menjadi padat dan keras. Kadar air yang tinggi akan menurunkan kualitas suatu bahan bakar, karena kadar air yang tinggi akan menurunkan nilai kalor bakar.

Dari Gambar. 2 dan Gambar 3 juga dapat dilihat bahwa kadar abu dan kadar air kedua jenis briket biji plastik lebih rendah dari kadar abu dan kadar air batu bara fine coal yang digunakan di kiln Indarung IV, sehingga briket biji plastik dapat digunakan sebagai pengganti batu bara di kiln Indarung IV PT Semen Padang. 


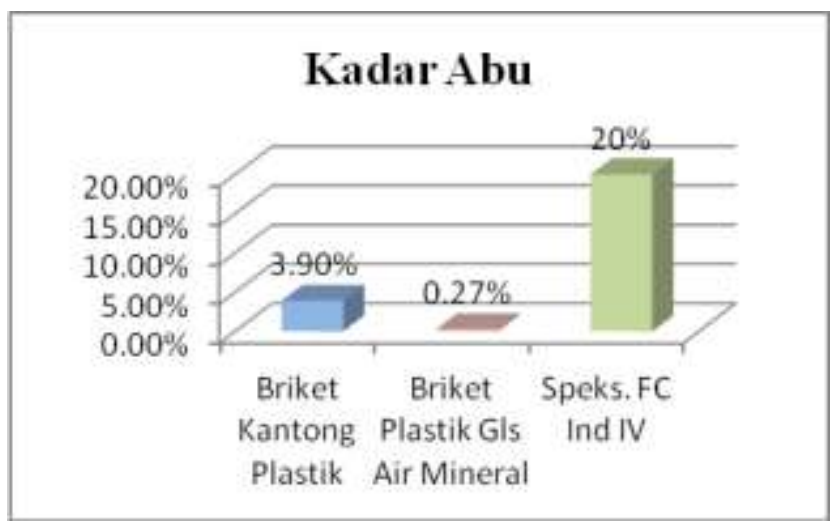

Gambar .2 Perbandingan Kadar Abu Briket Biji Plastik

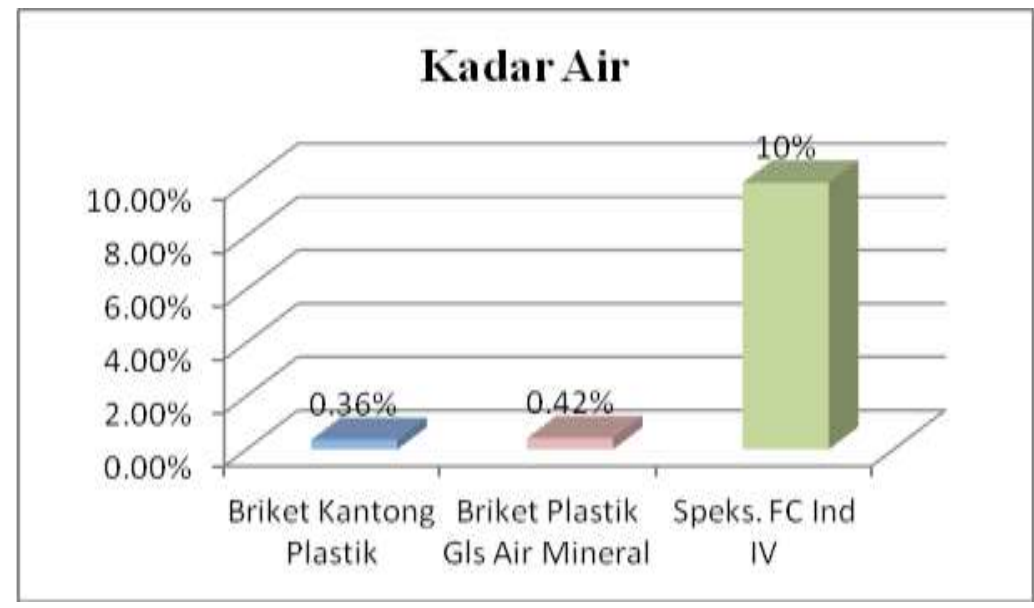

Gambar .3 Perbandingan Kadar Air Briket Biji Plastik

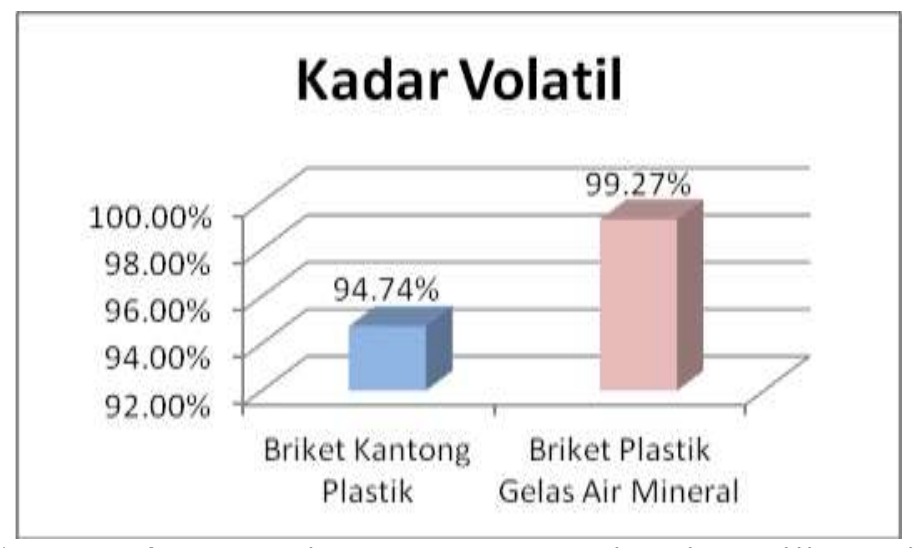

Gambar .4 Perbandingan Kadar Volatil Briket Biji Plastik

Pada Gambar .4 terlihat perbedaan kadar volatil dari kedua jenis briket sampah plastik :

Kadar volatil adalah jumlah zat yang menguap pada senyawa hidrokarbon pada pemanasan $900^{\circ} \mathrm{C}$ dalam keadaan miskin oksigen. Kadar volatil juga menunjukkan seberapa cepat suatu material akan terbakar ketika diberikan panas. Semakin panjang ikatan rantai atom suatu senyawa hidrokarbon maka akan semakin banyak zat menguap pada saat pemanasan. Dari Gambar .4 di atas terlihat bahwa kadar volatil briket dari sampah plastik gelas air mineral lebih tinggi dari kadar volatil briket dari sampah kantong plastik. Hal ini disebabkan karena briket dari sampah plastik gelas air mineral memiliki ikatan rantai hidrokarbon yang lebih panjang dibandingkan briket dari sampah kantong plastik. 


\section{Perbandingan Jumlah Pemakaian Batu Bara dan Briket Plastik di Kiln Indarung IV PT Semen Padang}

Perbandingan jumlah pemakaian batu bara fine coal dengan briket biji plastik dapat dilihat pada Tabel .3 berikut ini :

Tabel .3 Perbandingan Jumlah Pemakaian Batu Bara Fine Coal Kiln Indarung IV dengan Briket Plastik

\begin{tabular}{|c|l|c|}
\hline No & \multicolumn{1}{|c|}{ Jenis Bahan Bakar } & $\begin{array}{c}\text { Rata-Rata } \\
\text { Pemakaian }\end{array}$ \\
\hline 1 & Fine coal Kiln Indarung IV & 35 ton/jam \\
\hline 2 & Briket kantong plastik & $\begin{array}{c}18,70 \\
\text { ton/jam }\end{array}$ \\
\hline 3 & $\begin{array}{l}\text { Briket plastik gelas air } \\
\text { mineral }\end{array}$ & $\begin{array}{c}17,45 \\
\text { ton/jam }\end{array}$ \\
\hline
\end{tabular}

Data pada tabel di atas juga dapat di lihat dalam bentuk grafik seperti pada Gambar .5 berikut ini :

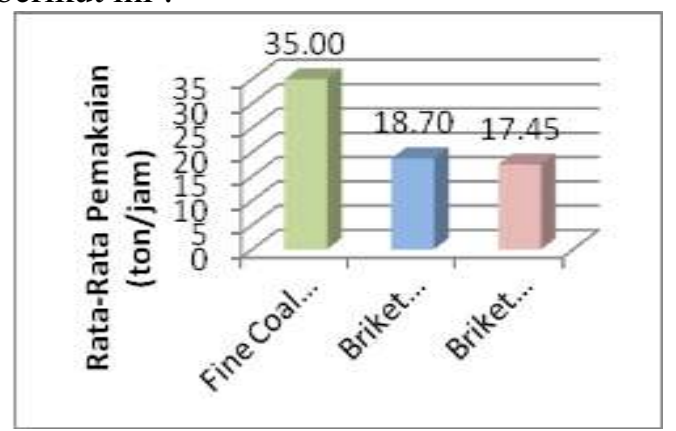

Gambar. 5 Perbandingan Jumlah Pemakaian Batu Bara Fine Coal Kiln Indarung IV dengan Briket Plastik

Dari Tabel .3 dan Gambar .5 dapat disimpulkan bahwa perbandingan jumlah pemakaian batu bara fine coal kiln Indarung IV dengan briket biji plastik adalah :

1. Batu bara : Briket kantong plastik

$=35$ ton/jam : 18,70 ton/jam

$=1: 0,53$

2. Batu bara : Briket plastik gelas air mineral

$=35$ ton/jam : 17,45 ton/jam

$=1: 0,50$

\section{KESIMPULAN}

Dari penelitian dan pengolahan data yang telah dilakukan, maka kesimpulan dari penelitian ini adalah :

1. Kalor bakar briket plastik dari bahan baku sampah kantong plastik adalah $10.112 \mathrm{kal} /$ gram, dengan kadar abu $3,90 \%$, kadar air 0,36\% dan kadar volatil $94,74 \%$. Kalor bakar briket biji plastik dari bahan baku sampah plastik gelas air mineral adalah 10.844 $\mathrm{kal} /$ gram, dengan kadar abu 0,27\%, kadar air $0,42 \%$ dan kadar volatil 99,27\%. Dari data tersebut dapat disimpulkan bahwa briket plastik dari bahan baku sampah plastik gelas air mineral lebih baik kualitasnya.

2. Dari kualitas briket plastik yang telah diketahui, jika dibandingkan dengan spesifikasi batu bara fine coal kiln Indarung IV PT Semen Padang, maka kualitas briket biji plastik lebih baik dari pada spesifikasi batu bara fine coal kiln Indarung IV PT Semen Padang, yang mana nilai kalor bakar briket plastik dari sampah plastik lebih tinggi $4.512-4.912 \mathrm{kal} /$ gram dan nilai kalor bakar briket biji plastik dari sampah plastik gelas air mineral lebih tinggi 5.244 - $5.644 \mathrm{kal} / \mathrm{gram}$ dari pada nilai kalor batu bara fine coal yang sesuai dengan spesifikasi kiln Indarung IV PT Semen Padang, sehingga briket biji plastik dapat digunakan sebagai bahan bakar pengganti batu bara di kiln pabrik Indarung IV PT Semen Padang.

3. Perbandingan jumlah pemakaian batu bara dengan briket kantong plastik berdasarkan spesifikasi batu bara fine coal kiln Indarung IV PT Semen Padang adalah 1:0,53. Dan perbandingan jumlah pemakaian batu bara dengan briket plastik gelas air mineral berdasarkan spesifikasi batu bara fine coal kiln Indarung IV PT Semen Padang adalah $1: 0,50$.

\section{DAFTAR PUSTAKA}

Afdhal, Borris dkk. 2013. Studi Timbulan, Komposisi dan Potensi Daur Ulang Sampah Kawasan PT Semen

Padang. Jurnal Teknik Lingkungan UNAND 10 (2) : 111-118, (http://lingkungan.ft.unand.ac.id/imag es/fileTL/Dampak10 -2/4-YMD.pdf, diakses 14 Agustus 2015)

Asip, Faisol dkk. 2014. Pembuatan Briket dari Campuran Limbah Plastik LDPE, Tempurung Kelapa dan Cangkang Sawit. Jurnal Teknik Kimia, No. 02 Vol. 20, (http://jtk.unsri.ac.id/index.php/jtk/art 
icle/viewFile/169/168, diakses 02 Juli 2015)

Badan Standarisasi Nasional. 2000. SNI 016235-2000 Tentang Briket Arang. Jakarta : Badan Standarisasi Nasional.

Badan Standarisasi Nasional. 1991. SNI 19. 2454-1991 Tentang Tata Cara Teknik Pengolahan Sampah Perkotaan. Jakarta : Badan Standarisasi Nasional.

British Standart. 1997. BS 1016 : Methods for Analysis and Tensting of Coal and Coke. Inggris : British Standart.

Chandrianto. 2012. Pengelolaan Persampahan. Padang : Sekolah Tinggi Teknologi Industri Padang.

Dharini, Mega dan Yulinah Trihadiningrum. 2010. Studi Terhadap Timbulan Sampah Plastik Multilayer serta Upaya Reduksi yang Dapat Diterapkan di Kecamatan Jambangan Surabaya. Jurnal Penelitian,

(http://digilib.its.ac.id/public/ITS-

Undergraduate-15498-3306100067-

Paper, diakses 02 Juli 2015)

Ervil, Riko dkk. 2013. Panduan Penulisan dan Ujian Skripsi. Padang : Sekolah Tinggi Teknologi Industri Padang.

Hadi, Arif Ismul. 2012. Analisis Kualitas Batu Bara Berdasarkan Nilai HGI dengan Standar ASTM. Jurnal Ilmu Fisika Indonesia, Vol. 01 No. 01, (https://jsimetri.files.wordpress.com/2 012/06/v1-no1-09-arif-37-41.pdf, diakses 25 September 2015)

Hambali, Erliza dkk. 2007. Teknologi Biobriket. Bogor : PT.Agromedia pustaka.

Mardiana, Gatot, dan Rahardi Mahadika. 2010. Pemanfaatan Limbah Biomass Sebagai Bahan Bakar Alternatif dalam Kegiatan $\mathrm{Co}$ Processing di PT Semen Gresik. Seminar Rekayasa Kimia Dan Proses, ISSN 1411-4216, (http://eprints.undip.ac.id/19600/1/D14.pdf, diakses 02 Juli 2015)

Nizwardi, Azkha. 2006. Analisis Timbulan, Komposisi dan Karakteristik Sampah Di Kota Padang. Jurnal Kesehatan Masyarakat, I (1), (http://jurnal.fkm.unand.ac.id/index.p hp/jkma/article/view/5, diakses 14 Agustus 2015)
Nursanto, Edy. 2011. Keterdapatan dan Tipe Mineral Pada Batu Bara Serta Metode Analisisnya. Jurnal Teknologi Technoscientia, Vol. 4 No. 01 ,

(http://www.undana.ac.id/jsmallfib_to p/jurnal, diakses 24 September 2015)

Pamungkas, Yulius. 2010. Teknologi Co-

Processing : Solusi Alternatif Mereduksi Bahan Bakar Fosil dan Gas $\mathrm{CO}_{2}$ di Industri Semen Indonesia. Jurnal Rekayasa Proses, $\begin{array}{llll}\text { Vol. } & 4 & \text { No. } & \end{array}$ (http://jurnal.ugm.ac.id/ jrekpros/article/download/.../1695 diakses 02 Juli 2015)

PT Semen Padang. 2010. Spesifikasi Standar Internal PT Semen Padang. Padang : PT Semen Padang

Rizkivia, Deqi. 2010. Eko-Briket dari Komposisi Sampah Plastik High Density Polyethylene (HDPE) dan Arang Sampah Organik Kota. Jurnal Penelitian,

(http://digilib.its.ac.id/public/ITSUndergraduate-10085-Paper, diakses 14 Agustus 2015)

Suharto. 2010. Rancangan Produk Bahan Plastik Daur Ulang Sebagai Upaya Peningkatan Industri Kreatif. Jurnal Rekayasa, (http://polines.ac.id/ rekayasa/upload/jurnal/jurnal rekayasa 1335760925.pdf diakses 02 Juli 2015)

Sumadi. 1998. Metodologi Penelitian. Jakarta : Universitas Gadjah Mada.

Surono, Untoro. 2013. Berbagai Metode Konversi Sampah Plastik Menjadi Bahan Bakar Minyak. Jurnal Teknik Vol. 03 No. 01, (http://jurnalteknik. janabadra.ac.id/wpcontent/uploads/2014/03/05-ArtikelUntoro-Revisi.pdf, diakses 02 Juli 2015)

Surya, Supeno. 2005. Dioxin Free. Medan : Pustaka Nasional.

Wahyu, Dian, dan Ruzita Sumiati. 2009. Analisi Energi Pada Sistem Rotary Kiln Unit Indarung IV PT Semen Padang. Jurnal Teknik Mesin Vol. 6 No.02,

(http://download.portalgaruda.org/arti cle.php. article $=57943 \&$ val $=43$, diakses $02 \quad$ Juli 2015 
